\title{
Placing the distant other on the shelf: An analysis and comparison of (fair trade) coffee packages in relation to commodity fetishism
}

\author{
by Robbe Geysmans and Lesley Hustinx \\ Ghent University; Ghent University \\ Sociological Research Online, 21 (1), 6 \\ <http://www.socresonline.org.uk/21/1/6.html> \\ DOI: $10.5153 /$ sro.3854
}

Received: 31 Mar 2015 | Accepted: 4 Jan 2016 I Published: 28 Feb 2016

\begin{abstract}
Fair trade has been praised for 'de-fetishizing' commodities by providing consumers with information on the production of the commodity. Various empirical studies of fair trade marketing materials have generated critique of this vision. However, these focused on materials produced by engaged fair trade organizations. As the fair trade concept has entered the mainstream, fair trade products have found their way into supermarkets. In this setting, these products are confronted with competition, both internal (with other fair trade products) and external (with non-fair trade products). In this article, we argue for a broader focus when studying the relationship between fair trade and defetishization. Our argument is based on a study of whether and how defetishization is advanced on packages of ground coffee within the retail landscape of Flanders, Belgium. Several categories of packages can be distinguished, based on brand (e.g., fair trade advocate, regular brand, retailer house brand) and label (e.g. fair trade label; other social label; no label, but origin is emphasized in the product name). We demonstrate the difficulty of distinguishing these packages based on the visual and textual information they carry (beyond the label), which complicates the identification of any clearly distinct 'fair trade message' on these packages. Instead of serving a clear 'defetishizing' function, these messages are mixed, interchanged, and adapted. We argue that this could be a direct consequence of perceived or actual changes in the consumer publics inherent to the mainstreaming of fair trade.
\end{abstract}

\author{
Keywords: Fair Trade, Commodity Fetishism, Mainstreaming, Marketing, Ethical \\ Consumption
}

1.1 Although fair trade products represent only a small segment within the consumer market, they continue to grow in popularity. [1] In 2013, global sales of products certified through Fairtrade International amounted to $€ 5.5$ billion, a 15\% increase as compared to 2012 (Fairtrade International 2014). According to Webb (2007), this indicates the influence of organized consumer activism and the politicization of consumption. Moving beyond the pervasive image of a passive consumer in the grip of global corporations' seductive marketing techniques, scholars in the sociology of consumption and political sociology have become interested in studying fair trade's potential to reconnect consumers and producers by revealing the social relationships underlying production and exchange (Hudson \& Hudson 2003). This reconnection is thought to be achieved by combining the creation of an alternative trade system with the provision of information to consumers concerning the origins and production processes associated with specific products, as well as about how consumption of a product affects its producers and their living and working conditions (Fridell 2007; Hudson \& Hudson 2003; Lyon 2006). In this sense, fair trade is often perceived as 'removing the veil' (Hudson \& Hudson 2003) from what Marx referred to as 'commodity fetishism': 'a condition within capitalism in which the social relationships through which commodities are produced are obscured in the commodity as it appears in the market' (Allen \& Kovach 2000: 225). Given that commodity fetishism 'is pervasive and intensifying,' it 'has crucial implications for our collective abilities to recognize and address the forms of environmental and social destruction unfolding within the social relations of capitalist production' (Hudson \& Hudson 2003: 414).

From this perspective, critical sociological analysis of the potential of the fair trade market to 'defetishize the commodity' is highly relevant (Hudson \& Hudson 2003; Webb 2007). Several empirical studies have pursued this line of research, investigating marketing materials, including advertisements, websites and catalogues (Bryant \& Goodman 2004; Goodman 2004; Varul 2008; Wright 2004; 2009). Because these studies focus predominantly on the distinct marketing materials of engaged fair trade organizations, however, they advance the notion of a relatively homogeneous fair trade message. In this sense, existing research has not sufficiently 
a process of mainstreaming (Doherty et al. 2013; Geysmans forthcoming; Low \& Davenport 2005a; 2005b; Moore 2004; Raynolds 2009; Webb 2007). The term 'mainstreaming' refers to a process in which an increasing number of products labeled as fair trade are now being offered by conventional companies. They are thus being sold not only by specialized 'niche' retailers (e.g., world shops), but also in ordinary supermarkets. Within this setting, fair trade products are positioned in a much more competitive environment, both internally (competition between fair trade certified products) and externally (with products bearing other labels, or no label at all).

The consequences of mainstreaming and increased competition for fair trade's potential to erode commodity fetishism are insufficiently understood. Given that the Fairtrade label was originally intended 'to address the "problem" of distinguishing fairly traded coffee from established, branded products, and of destabilizing the meanings and qualities attributed to the latter' (Webb 2007: 5.6.), the mainstreaming of fair trade and the proliferation of other labels risks undermining the distinctive and supposedly politicizing nature of fair trade (e.g., Watson 2006). Some scholars have even argued that fair trade has become simply another 'niche,' subject to marketing techniques similar to those used with other products within an overall corporate strategy to increase profit. According to this argument, therefore, the growth in fair trade sales is no longer critically dependent upon public awareness and the understanding of global commodity chains (Alexander \& Nichols 2006; Goodman 2010).

This article aims to make an original contribution to the debate, based on the textual and visual analysis of various product packages in the supermarket setting. The consideration of different groups of product packages is indispensable to providing a more accurate reflection of the 'heterogeneous' landscape that characterizes the supermarket shelf. We regard packages as key devices for providing information to customers and thus for potentially achieving defetishization at the point of purchase. We consider whether and how defetishization can be achieved through the textual/visual information appearing on product packages associated with various brands and labels. By identifying key dimensions of distinction and similarity, we aim to develop a more complex and relational conception of the defetishizing potential of fair trade products at the point of purchase. The findings of this study thus provide a much-needed basis for enhancing understanding with regard to the relationship between consumers and supermarkets in the context of ethical consumption and consumer activism.

After providing a brief description of commodity fetishism and how fair trade has been argued to challenge this phenomenon, we discuss developments in fair trade marketing and provide a critical presentation of the relationship between fair trade marketing and commodity fetishism. Subsequently, we elaborate on reasons for focusing on product packages in a supermarket setting, in addition to introducing the data and methods used in our empirical study. In the findings section, we focus upon the ways in which packages frame the producer, the process and the place of production.

\section{Commodity fetishism and fair trade}

2.1 As stated above, we proceed from the point that fair trade has been lauded for addressing the problem of commodity fetishism (Hudson \& Hudson 2003; Lyon 2006). In the first volume of Capital, Marx uses the notion of 'commodity fetishism' to describe a condition in capitalist society, in which commodities seem to be detached from the labor from which they emanated, such that exchange value is perceived as inherent to an object. In this way, the labor process 'behind' the product is hidden from view:

The mysterious character of the commodity-form consists therefore simply in the fact that the commodity reflects the social characteristics of men's own labour as objective characteristics of the products of labour themselves, as the socio-natural properties of these things' (Marx 1976 [1867]: 164)

Broadly interpreted, the notion of commodity fetishism can thus be used to 'refer to the ignoring or denial of the background of objects' (Carrier 2010: 674). In this context, David Harvey notably speaks of 'silent grapes': 'The grapes that sit upon the supermarket shelves are mute; we cannot see the fingerprints of exploitation upon them or tell immediately what part of the world they are from' (Harvey 1990: 423).

In contrast, fair trade products are supposed to 'shout' about their origins and production process (Goodman 2004: 893). In this respect, the provision of information to customers is arguably a key factor in defetishizing commodities (Hudson \& Hudson 2003; Lyon 2006; Watson 2006). It does not suffice for the actual production and trading process within fair trade systems to differ from 'conventional' systems (e.g., more durable trade relations, investments in social development), thus interfering with circumstances at the basis of commodity fetishism. Defetishization also requires consumers who are better informed about all the elements connected to the production of a specific commodity. According to Alexander and Nicholls (2006), 'connectivity' between producers and consumers forms an essential part of fair trade systems, thus 'shortening' the geographic distance between production and consumption by 'lengthening' the communications network between consumers and producers (Alexander \& Nicholls 2006: 1240). Goodman (2004) argues that this should be accomplished by adding specific 'translation devices' in the form of discursive and visual narratives to the network. Within the fair trade market, these discursive and visual narratives are often contained in marketing materials (e.g., brochures, 


\section{Defetishizing or refetishizing? Developments in and critical studies of fair trade marketing}

This emphasis on fair trade marketing entails an apparent contradiction, as marketing has been identified as a development within the contemporary trade system that has 'served to further divorce the end product from the process by which it was produced' (Hudson and Hudson 2003: 417). Although Hudson and Hudson (2003) note that fair trade uses marketing to advertise about the process of production, other authors have acknowledged that fair trade marketing has undergone drastic changes. For example, Alexander and Nicholls (2006) identify three evolutionary phases in fair trade marketing. The first phase was characterized by communication emphasizing the production process. In an effort to move beyond the 'natural' consumer of fair trade products, however, the focus of fair trade marketing shifted toward an emphasis on product quality and, more recently, places (e.g., fair trade towns) (Alexander and Nicholls 2006). Also Goodman (2010) argues that shifts in fair trade marketing have taken place, which has recently led to the extensive use of celebrities (i.e., celebritization) in fair trade campaigns.

Given the clear development of fair trade marketing beyond issue awareness, the tension - and even contradiction - inherent in regarding marketing materials as potential defetishization tools seems to be increasing. Several empirical studies on fair trade marketing materials have generated critiques that undermine the unquestioning acceptance of fair trade marketing as contributing to the defetishization of commodities. Major critiques relate to the portrayal of producers and geographic origins in fair trade marketing. First, the images of producers used in fair trade marketing have been labeled romanticized and, in certain ways, even neo-colonial (Varul 2008). It is the use of romanticized/simplified images that commodifies the lives of the producers, and the consumer/producer relationship itself, thus 'refetishizing' fair trade commodities (Wright 2004). As observed by Michael Goodman (2004), this constitutes a process of re-working the commodity fetish. A second critique is that fair trade marketing is not free of Edenic Myths (Bryant \& Goodman 2004). As argued by Wright (2004), images and descriptions of landscapes in fair trade advertisements tend to be overly 'natural,' and thus romanticized.

Given the presence of these romanticized images (of both producers and landscapes), Goodman (2004) clarifies how fair trade can be linked to the 'double commodity fetish,' as described by Cook and Crang (1996). Cook and Crang describe contemporary market actors that emphasize the geographic origins of products in order to 're-enchant' commodities (Cook and Crang 1996). In addition to veiling certain information, an extra veil of romanticized information is added to a commodity, thereby establishing a double commodity fetish. For example, Bell and Valentine (1997) refer to 'exotic' fruit as a product in which the origins are promoted as a unique selling proposition, closely related to the notion of 'authenticity.' In this sense, images of distant places are apparently used to offer opportunities for 'imaginative travel' (Urry 2000; 2007), transporting people to the other side of the world without physically moving. Given the romanticized nature of these images, however, they do not seem appropriate tools for defetishization.

\section{Fair trade products going mainstream: Competition on the supermarket shelf}

Our literature review reveals important critical insights into the relationship between fair trade marketing and defetishization. Nevertheless, existing research focuses primarily on the marketing materials produced by engaged fair trade organizations. The full understanding of this relationship also requires considering marketing materials produced by other actors who seem to be/are situated in the fair trade market, as they characterize the process of fair trade mainstreaming. To this end, we adopt the novel approach of examining a range of product packages found in the supermarket setting.

Product packages play a central role in providing information at the point of purchase. As argued by Hudson and Hudson (2003), fair trade attempts to make the 'conditions in which commodities are produceda very visible part of the product (419, emphasis added). First, product packages carry fair trade labels, which are intended to provide certain reassurances to consumers. For the fair trade movement, labeling is a key strategy with which 'to distinguish, and impute meaning to, an alternative product' (Webb 2007: 5.3). Second, the texts and images provided on a package can provide more explicit information on a variety of issues. Packages can thus be considered prime sources of information about products, revealing, emphasizing, or hiding their visible and invisible characteristics (Barrey et al. 2000). Packages thus offer a 'frame' (Goffman 1974) through which customers can make sense of the products they see. The essential role of packages in framing relates to their crucial role in defining the 'skills, activities and identities of consumers' (Cochoy 2007: 111). operates within a more diversified market setting. The defetishization literature has yet to reflect sufficient acknowledgement that the introduction of fair trade products into the supermarket has brought these product packages into a setting of both internal and external competition. Internal competition results from the nature of the fair trade label. Although fair trade standards are not legal standards, the most widely known national fair trade labels are united under the international umbrella of Fairtrade International. This organization sets standards for certifying producers and products with the Fairtrade label. In practice, this implies that, with the 
established industries which understood the subtleties of local markets and were already well known' (Renard 2005: 423). As fair trade products become more numerous - and are not only sold by engaged fair trade organizations -, they are thus forced to compete 'among themselves' for the attention of the customer. Obviously, there is also external competition with similar products that are not certified as fair trade. Moreover, labels have been developed that make claims that resemble those made by the fair trade movement (Hudson \& Hudson 2003; Hudson et al. 2013; Arnold \& Hasse 2015). Although the various labels are not at all interchangeable (e.g., Raynolds et al. 2007), they arguably could be confusing to consumers, who do not necessarily make clear distinctions (e.g., Renard 2003; Hudson et al. 2013; Watson 2006).

Through analyzing a range of different product packages found on the supermarket shelf, we capture this situation of market competition and diversification.

\section{Data and methodology}

\section{The case of coffee}

5.1 Our analysis focuses on packages of ground coffee. This choice is motivated by three arguments. First, coffee has a clear link to fair trade. It is the earliest commodity labeled as fair trade, and it currently remains one of the most popular fair trade products (Fairtrade International 2014; Raynolds et al. 2004; Webb 2007). Second, many supermarkets currently offer fair trade ground coffee. Third, aside from (or in addition to) fair trade labels, the world of coffee is characterized by a wide array of other labels and certificates (Raynolds et al. 2007; Reinecke, Manning \& von Hagen 2012, many of which are associated with 'caring for the distant producer.'

We studied the packages of ground coffee sold in the five dominant supermarket chains in Flanders (the Dutch speaking part of Belgium). When visiting these supermarkets, we used two main criteria to select coffee packages for our database. The first concerned the presence of a 'social' label or certificate (emphasizing the impact on living/working conditions for the producer). Products carrying such labels/certificates were added to the database. We should note here that although such labels formed an essential selection criteria, the analysis extended further to include other visual and textual information on the selected packages. The second selection factor concerned the name of the coffee. Packages bearing names referring to the place of production (e.g., 'Brazil,' 'Indonesia') were also included in the database (regardless of whether they carried any labels/certificates). Note that, to ensure the inclusion of all varieties of fair trade ground coffee from one fair trade organization, all of its varieties were included in the database, even though only one variety was sold in one of the 'big five' supermarket chains (the other varieties were sold in a chain of organic shops owned by one of these chains and/or in specialized fair trade shops). Data collection took place in the spring of 2013.

\section{Analytical strategy}

As elaborated earlier in this paper, the fair trade literature often tends to treat the notion of defetishizing commodities in terms of consumers gaining insight into commodities' production. Scholars typically focus on the provision of information concerning such issues as the place of production, the process of production, and the people involved in production (e.g., Goodman 2010; Hudson \& Hudson 2003; Lyon 2006). These three issues form the focus of our analysis of the information found on the packaging of ground coffee. As mentioned, these packages can be regarded as providing a frame to the customer. Advanced by Goffman (1974) as a basic tool for shaping social interaction, a frame is essentially a way in which people make sense of a given reality (or information about that reality). Rein and Schön (1993: 146) adopt a relatively broad definition of the concept: 'framing is a way of electing, organizing, interpreting and making sense of a complex reality to provide guideposts for knowing, analyzing, persuading, and acting.' In our analysis of whether and how defetishization is advanced on coffee packages, we thus focus on the framing of information concerning producers, process, and place of production. When coding the information found on the packages, we focused on the presence of references to producers, process, and place of production, as well as on the messages associated with these references. The coding was applied to meaningful fragments of text, and not to individual words.

\section{Expectations concerning different packages}

We divided the coffee packages in our database into four categories (Table 1). The first category includes packages sold by 'fair trade advocates' (i.e., organizations whose primary goal is to promote and sell fair trade products). The second category consists of packages sold by conventional brands and retailer house brands that have adopted the Fairtrade label on at least some of their products. The third category includes packages bearing other labels or certificates claiming to benefit the living and/or working conditions of producers (thus excluding claims focusing exclusively on health or environment). The fourth category consists of packages without any social label, but with names that clearly refer to the place of production. 


\begin{tabular}{|l|l|l|l|l|}
\hline & Brand & Social Label & Origins in name & $\begin{array}{l}\text { Nr of packages in } \\
\text { category }\end{array}$ \\
\hline 1. & Fair trade advocates & Fairtrade & Sometimes & 2 \\
\hline 2. & Regular and retailer house brands & Fairtrade & Sometimes & 6 \\
\hline 3. & Regular and retailer house brands & $\begin{array}{l}\text { Other, non- } \\
\text { Fairtrade }\end{array}$ & Sometimes & 5 \\
\hline 4. & Retailer house brands & No & Always & 5 \\
\hline
\end{tabular}

Different expectations can be formulated with regard to the information provided on the packages in each of the four categories. First, the packages of 'fair trade advocates' are likely to contain considerable information on producers, conditions, and place of production, as these products are marketed by organizations strongly engaged with fair trade. Second, packages of regular brands and retailer house brands bearing fair trade labels are likely to provide less information on these issues. Although studies on the defetishizing aspect of fair trade have yet to address the distinction between fair trade products sold by fair trade advocates and those sold by regular companies, we base this expectation on the fact that none of the regular brands in our database exclusively offer products certified as fair trade. If they were to provide a substantial amount of information on issues relating to 'fair' production and trade, they might ultimately direct attention toward unfair practices within their broader product range. Third, communication on the packages of brands with other labels is unlikely to offer any profound revelations concerning the production process. We expect this because many of these labels are identified as 'substitute labels' (Hudson et al. 2013: 138), which are actually 'certifications that largely hold the bar on existing standards to foster corporate engagement' (Raynolds et al. 2007: 159). Finally, products without labels, but with names stressing origins are likely to refer to the origins of the product, but in a manner that actually invokes a 'double commodity fetish' (Cook \& Crang 1996).

In the remainder of this article, we focus on our findings concerning the framing of 1) the producer, 2) the process of production, and 3) the place of production on the various product packages. In the following sections, the quotations from packages were originally in Dutch and translated by the authors, unless explicitly mentioned otherwise. When referring to specific packages, we use the package numbering presented in Table 2 (in the appendix).

\section{Findings}

\section{The producer}

\section{Bringing the producer into the picture}

The first features to draw attention are the images on the product packages. It is interesting to note that only the packages of the fair trade advocates displayed clear images of coffee farmers (or people representing them). Other coffees with fair trade labels displayed only hands (supposed to be those of the producers) or no visual reference to the producer at all. As different authors have shown, a critical lens is needed when viewing representations of producers. This is because, although such representations may be interpreted as a means of defetishization, 'in fact, social relations are but partially revealed, in ways that render them commodities in their own right' (Wright 2004: 671). On the fair trade advocates' packages we examined, the images clearly portrayed romanticized (Varul 2008) stories in certain ways. First, the vast majority of the individuals portrayed on these packages were smiling into the camera lens, as if smiling to Northern consumers (Fig 1). These pictures are thus clearly framed within the idea of fair trade's positive impact on producers' lives (in Wright's terms, the 'happy ever after' story [2004: 671]). At the same time, however, they conceal the hardships of growing coffee. Second, the packages of two coffee-varieties of one fair trade advocate (Packages 5) use images of people who do not appear to represent the producers, instead highlighting the geographic origins of the product (Fig $1 \mathrm{~A})$. The individuals on these packages seem to represent their countries or continents by wearing traditional clothing (or at least clothing that consumers are likely to perceive as traditional). By stressing the 'otherness' of the people portrayed, spatial distance is apparently magnified rather than minimized. Goodman's (2004) argument regarding how standardized images and ideas about the exotic other seem to 're-work' the fair trade fetish appears to apply here. As formulated by Jackson (1999), images of people in exotic clothing might constitute an illustration of the 'commodification of culture,' emphasizing differences by using a frame of authenticity and tradition. 
It is interesting the front of two

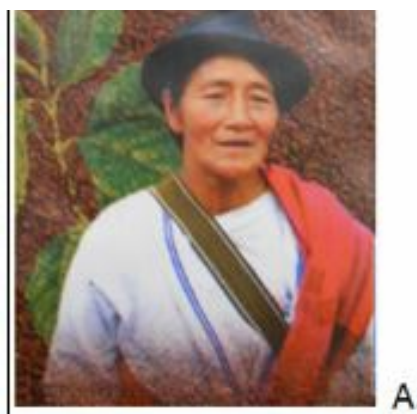

A.

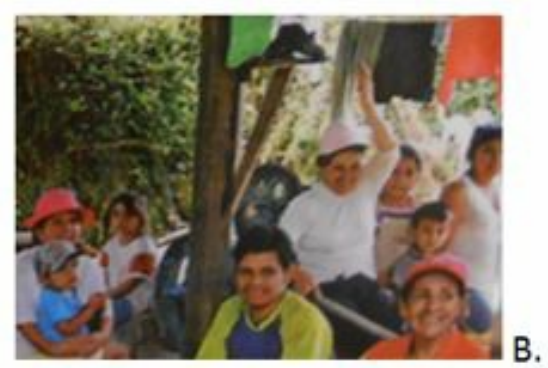

on the other two varieties are not wearing such obviously traditional' elothing. Moreverer, the images on the back of the packages are more clearly intended to represent the coffee producer. For example, some depict people on a coffee farm, thus making it easy to identify them as producers. Moreover, many images depict the producers within a broader context (e.g., the family or the cooperative; see Fig. 1B). Producers are thus not presented as isolated entities, but as part of a group. The packages of the other fair trade advocate (Packages 7$)$ place even more emphasis on the portrayed person as a producer (Fig 1C \& D). All of these images depict one person in the act of producing coffee (e.g. picking, or weighing). The depiction of both women and men avoids providing a unidimensional vision of the male coffee producer, as identified in Wright's data (2004: 668).

Given the visual representation of the growers, most of the pictures on the fair trade advocates' packages seem aimed at providing at least some information on the people who produced the coffee. Although this might support the defetishizing character of fair trade, the use of specific romanticized images might add another layer to the fetish (e.g., Lyon 2006; Varul 2008). It is interesting to note that the other coffee packages (both with and without fair trade labels) do not carry such visual representations of the producers. In this respect, these coffee packages do not correspond to the notion of defetishizing the commodity and shortening the distance between production and consumption.

\section{Speaking about producers}

Most of the packages carry written messages about the producers. The packages of the two fair trade advocates contained textual elements referring to individual producers or cooperatives. One (Packages 5) accomplished this by naming the specific producer organizations/cooperatives that produced the coffee, explaining how they work and benefit the producers. Customers can thus learn how a cooperative brings several families together, and how these families benefit from the cooperative (e.g., through access to microcredits). This information -provided under the heading 'Effects' on the back of the package- apparently addresses consumers as people who are moved to purchase by the product's socially just background. For example, customers can learn that 'the co-operation [...] has seen its role in local development been strengthened. It has been able to provide many services to its members, such as access to credit for the purchase of agricultural machinery' (Packages 5). Remarkably the text represents the benefits gained by producers, as mediated by the cooperative. The direct role of the consumer is stressed in a brief standard text, stating that, by buying the product, the consumer is helping to improve living and working conditions for the producer.

The texts included on the packages of the other fair trade advocate (Packages 7) presented individual producers. The images on the packages were accompanied by brief texts rendered in English handwriting on the back of each package (thus emphasizing authenticity, even though the original messages probably have been in Spanish, French, or Swahili). In these short texts, the producers greet the consumers, introduce themselves, and briefly tell something related to the coffee purchased. This brief introduction is followed by a link to a website, where consumers can read the 'stories' of specific producers. As stated by Wright, the relationship 'is, of course, visual, virtual, and entirely one-way' (2004: 671; see alsoLyon 2006). Nevertheless, it creates a situation in which the abstractness associated with distance is surpassed and replaced by concrete faces to which customers can relate the coffee they drink. One rather disturbing observation involves the framing of this relationship on some of the packages of this fair trade advocate. Some of the brief citations reflected a hierarchical relationship between the consumer and the producer. For example, some texts contained statements 
coffee' (Packages 7, in English). It is difficult to regard the relationships portrayed in such statements as equal. Varul (2008) observes that, despite the goal of promoting equality in trade relationships, fair trade advertising often builds on images relating to colonial inequality. For example, a short text on one of the packages states: 'Meanwhile, think about the farmer who carefully selected these coffee beans. Know that he and his family got a good price and that you've made a difference in their lives' (Packages 7, in English). In this case, it is the privilege of the consumer to consume, while the producer is portrayed as a provider. The idea of consumers who are moved to action by claims about social justice is merged with a notion of consumers as people who also (or primarily) enjoy the position of being able to consume the product. Of course, as stated by Wright, the actual dependency of the producers on the coffee trade (whether fair or otherwise) is greater, given that 'all the consumer would be without is a particular coffee brand' (2004: 672).

Overall, the fair trade advocates seem to aim to bridge the distance between the consumer and the producer (albeit only in this direction) by establishing a personal bond between the coffee consumer and a symbolic representation of the person(s) who grew the coffee (Goodman 2004; Wright 2004, 2009). It is interesting to note that only two of the other packages (one with a non-fair trade label [Packages 8] and one without any label [Packages 9]), both belonging to the same retailer house brand) made any reference to a specific producer. Both provided the name of the plantation at which the coffee was grown. For packages bearing a fair trade label but that were not sold by fair trade advocates (Packages 2, 3, 6, 13, 14 and 17, the producer remained an undefined category, indicated only broadly, with such terms as 'farmers' or 'cooperatives.' These terms were used predominantly in relatively standard explanatory texts, briefly mentioning the fair trade label and how customers could obtain additional information on the subject through a general website (e.g., www.fairtrade.net, managed by Fairtrade International; www.fairtradebelgium.be, managed by Fairtrade Belgium [formerly known as Max Havelaar Belgium]). For example: 'The independent Fairtrade/Max Havelaar label guarantees you that this coffee is certified according to the international Fairtrade standards. By buying this coffee, you are contributing to better living and working conditions for farmers, while supporting the protection of the environment. Info: www. fairtradebelgium.be' (Packages 3). Although similar texts also appeared on the packages of the fair trade advocates, the regular and house brands' packages differed by providing only standardized abstract references to producers.

Packages bearing non-fair trade labels (Packages 1, 8, 11, 12 and 16) used similar abstract references to producers. One package bearing the Rainforest Alliance label included a statement that the company strives to achieve 'good working conditions and a decent wage for the coffee farmers (Packages 16). One retailer-specific label assured consumers that its guidelines 'guarantee the compliance of the social and environmental criteria and improves the living- and working conditions of the producers' (Packages 12). Although such texts might establish a connection between consumers and producers (as argued by Whatmore and Thorne 1997), the information was very brief, making it difficult for consumers to arrive at any concrete interpretation of circumstances at the local level. In such cases, the label could become a positive asset for the product, assuming that consumers have no need for detailed claims about social justice, instead being reassured by the label itself, which thus adds value to the product.

The packages of products with fair trade and other certifications (not belonging to the fair trade advocates) can sometimes be identified as following the strategy of using labels as positive assets. In some cases, the packages offered frames explicitly linking the brand to the positive attributes of social justice inherent to the label. The consumer is informed how company $\mathrm{x}$ 'does everything in its power to distribute Fairtrade products' (Packages 13,14) or can learn more about company y's efforts in the field of sustainability and our principal partner UTZ Certified' (Packages 11) on the company website. These examples illustrate how brands build their images at least in part by emphasizing activities that are intended to benefit producers. This issue is also closely related to the concept of 'fair-washing,' which refers to practices in which corporations try to 'confuse consumers into thinking that the products being sold are certified fair trade products (or are an equivalent) when they are not' (Reed 2009: 14). For example, the use of labels resembling the fair trade label could reflect the fairwashing strategy of 'captive certification.' In this case, corporations associate with or develop labels/certificates that resemble fair trade labels, but that do not provide the same high social standards, and that often align with business interests (Reed 2009; see also Hudson \& Hudson 2003). Although such labels can have their own value, they become problematic when they are mistaken for fair trade, as the standards emphasize different aspects of the production and trade process (e.g., Hudson et al. 2013; Raynolds et al. 2009). The similarity of standard texts referring to producers on packages bearing fair trade labels and those bearing other labels indicates how easily such mistakes could be made by consumers who are unaware of the exact content of the various certification schemes. To illustrate, we refer to a claim found on one coffee package bearing both retailerspecific and third-party labels. This package stated that 'the local producers are paid in accordance with market prices' (Packages 8). Although this might seem noble at first glance, it ultimately says nothing more than that the price paid to the producers is regulated by the market - a risk from which the fair trade movement aims to protect producers. 
producers, as identified in literature and our own analysis. Companies might thus explicitly decide to avoid using romanticized pictures of smiling producers wearing 'traditional' clothing or messages that could be interpreted as reflecting neo-colonial dependency of distant producers.

\section{Process and place of production}

6.10 In general, the product itself occupied the central position on all of the packages. Visually, this was clear on the packaging materials of both house brands and regular brands bearing fair trade or other labels (Fig. 2). On most of these packages, images of the actual product featured most prominently. Some packages ( 3 \& 6$)$ featured unprocessed coffee: coffee beans, sometimes presented by hands holding them (Fig. 2A). Others depicted the end product - a cup of coffee - as with Packages 1, 2, and 12 (Fig. 2B). Yet another group displayed a combination of both (Packages 13, 14, 16, and 17). In this case as well, several explanations are possible. The focus upon pictures of the product might signal the company's disinterest in or lack of knowledge about the producer. Alternatively, it could reflect a strategic decision to avoid relatively superficial representations of producers, or it might be a strategy inspired by the will to market the brand as coffee of good quality, without profiling it as an 'ethical' product (an image that is sometimes associated with poor quality). It is interesting to note that, in the UK, Goodman (2010) identifies how fair trade advocates' packages have started to eschew the use of images of farmers, while major brands do not (the opposite of our findings).

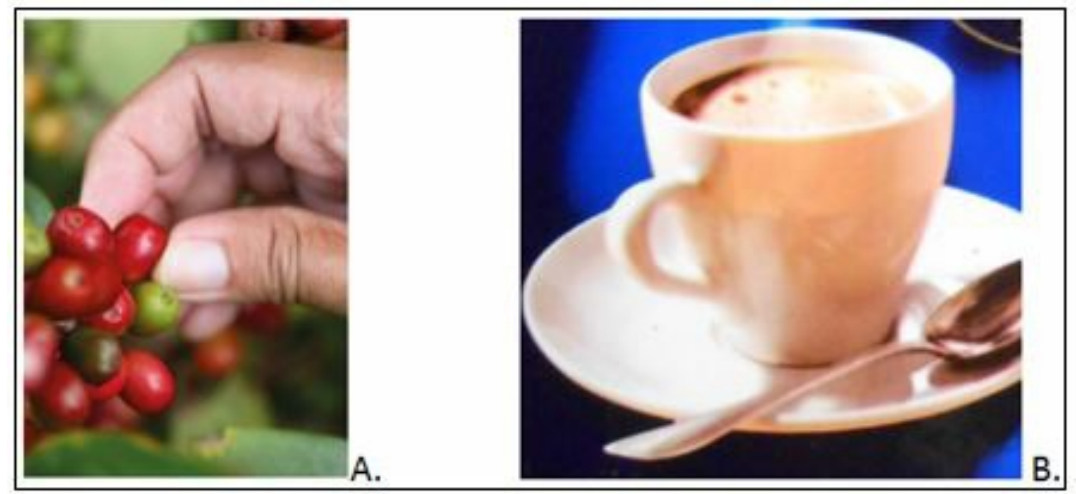

Figure 2. Product images

6.11 Quality appears to be a unifying element in the ways in which packages 'talk' about their coffee. Almost all packages (including those of the fair trade advocates) devoted a substantial amount of their space to convincing consumers of the quality of the product being sold. All but one of the packages (Packages $3, a$ retailer-specific brand of fair trade coffee) made explicit references to the quality of the coffee, usually by emphasizing excellent taste. For example, a package sold by one fair trade advocate noted that the coffee has 'a pleasant balance and fruitiness. The pleasant character is enhanced by a touch of acidity' (Packages 7). Others mentioned a 'sublime aroma,' 'pure delight (Packages 6), or 'subtle aftertaste of citrus and coriander' (Packages 9). In this regard, no straightforward distinctions could be made between categories. This finding corresponds to Wright's (2004) analysis of a fair trade advertisement, which contained a substantial amount of information intended to convince consumers that the product was 'better' (with much less reference to its ethical aspects). Studies in the marketing and business literature also indicate the importance of more hedonistic values in fair trade marketing (see De Ferran \& Grunert 2007; De Pelsmacker et al., 2005). From the perspective of defetishization our analysis provides more specific evidence of how quality can form a central frame when referring to both process and place of production.

\section{Producing quality}

6.12 Packages in every category contained explicit references to the process of production as the basis for the excellent quality of the coffee. In this context, the process of production refers to various stages of production, which were emphasized on specific packages: cultivation, roasting, and (in some cases) even packaging. For example, on one of its coffee varieties, one fair trade advocate argued that 'the use of coffees of the past and the method of growing under shady leaves provide this coffee with its strength, full taste, and abundance of flavors' (Packages 5). A package without a label but emphasizing origin stated that this $100 \%$ Arabica coffee was picked, washed, and dried using traditional methods, developing its unique flavor under these conditions' (Packages 9). The line of argumentation is clear: a specific characteristic of the process of production leads to the specific characteristics of the end product. This suggests that such information might actually defetishize the commodity, implying that it contributes 'to a greater understanding of the process by which the product was created, ' which Hudson and Hudson (2003: 418) argue is quite rare in advertising.

6.13 It is important to consider the extent to which such statements actually tell anything about the process of production. Except in the case of those who are unaware that coffee is grown, roasted, and packaged, 
'with special attention,' or 'with extensive experience' do not provide consumers with much additional insight into the production process. Only a few packages contained information on the production process that actually said anything about the social and environmental issues interwoven in this process. One example was on a package from a fair trade advocate, briefly mentioning that coffee grown in the shadow of trees secures biodiversity and protects the soil (Packages 5).

6.14 Many statements thus embellished the veil of fetishism instead of lifting it, through the use of romanticized descriptions of how 'only the ripe' (Packages 15) coffee beans have been 'selected with the greatest care' (Packages 4) and 'harvested by hand' (Packages 2), after which 'the master coffee roasters compose the most delicious blends in a traditional way' (Packages 8). Such statements left no room for information on the industrial side of coffee roasting, or the hardships inherent in the work on coffee plantations. This information might distract consumers away from the images of authenticity, care, and tradition. We are convinced that this issue is also essentially connected to the notion of 'shortening the distance' between producers and consumers; because the distance must be shortened, excessive complexity or distractions could potentially lead consumers away from the intended short route to the producer.

\section{The origins of quality}

6.15 During data-collection, we were surprised by the number of coffee packages which, through the name of the coffee, contained clear regional references to the origin of the raw commodity. This reminded us of Crang's statement that 'talking about a veil [central in the idea of commodity fetishism] misses how commodities talk loudly about where they may have come from, what places they want the consumer to think of and so forth' (Crang 1998: 133).

6.16 Some packages thus talk loudly about the landscapes in which the coffee was produced, enhancing the traceability of the product in an easily recognizable manner (Crang 1998). This practice is also familiar in the organics market, which is often dominated by potentially deceptive images of rural landscapes (Johnston et al. 2009). Bryant and Goodman (2004) - with a focus on products claiming to benefit the rainforest- comment on deceptive imagery with reference to 'Edenic Myth-making'. They demonstrate how specific images and narratives are used on product packages to refer to the rainforest as exotic, lush, or untouched, thus obscuring the political ecology of the rainforest. Wright (2009) argues how similar issues are sometimes at play in fair trade marketing.

6.17 The packages in our database reflected how the fair trade advocates (Packages 5 and 7) clearly referred to the regions in which the coffee was cultivated. Especially the packages of one of the fair trade advocates (Packages 5) carried different references to the place of production, which moreover were often strongly linked to the quality of the coffee. The landscape of production has thus been made functional: it yields good coffee (Cook \& Crang 1996). For example: 'On the slopes of Mount Kilimanjaro, one of the finest and most aromatic Arabica coffees in the world is grown. The height and fertility of the volcanic soil generate a slightly acidic coffee, full of rich and intense aromas' (Packages 5). In contrast to the illustrations identified by Bryant and Goodman (2004), these descriptions however are much less visual.The only visual image was generated by a small picture of the landscape on some of the brand's packages. These images did depict unspoiled scenery in which nature prevails.

6.18 The geographic references on the other fair trade advocate's packages (Packages 7) were not as extensive, often mentioning only the country of origin. Also in this case, the origins were combined with references to the high quality of the coffee, but not necessarily in a functional way (e.g., 'a coffee of top quality from the highlands of Lake Kivu'; Packages 7). Other packages of this fair trade advocate employed more 'Edenic' imagery in the 'advice' to the consumer: 'Buy this pack. Hurry home. Open it and smell the exotic scent of faraway places' (Packages 7, in English). This phrase commodified the origins as 'exotic' and open to the consumer's enjoyment.

6.19 None of the other packages with a label (fair trade or other) provided much detail on the origins. One brand mentioned the specific countries or regions of origin on the package (Packages 14), and on another brand's packages (Packages 2) an unclear picture of a sandy landscape provides the background to a picture of a coffee cup. A third brand's packages carried an image of a natural landscape and a sentence describing the location of the coffee plantation (Packages 8). References to the place of production were thus limited for both of these categories.

6.20 Packages in the fourth category (no label, but with a name emphasizing origin) used the distance between the place of consumption and the place of production as an exclusive characteristic of their coffee. For these coffees, origin and quality were intimately connected, with origin equaling quality. In this regard, they resembled the packages of the fair trade advocates (mostly packages 5), which also linked the origins of the coffee beans to the quality of the coffee. On the packages in the fourth category, however, the references were more extensive, containing more exotic superlatives. For example, one brand stressed the quality of its coffee's origin as follows: 'In the heart of the valley around Antigua, this plantation-grown coffee gathers all of its richness. 
of $1450 \mathrm{~m}$, the local farmers enjoy highly fertile land and the shadow of the Guatemalan tropical rainforest' (Packages 9). Another package of Guatemalan coffee stated that $98 \%$ of the coffee in Guatemala grows in the shadow of trees. This allows the coffee to grow more slowly, allowing top quality to develop. The best coffee comes from Antigua, a region in the southern part of central Guatemala, a volcanic region at the elevation of $1400 \mathrm{~m}-1700 \mathrm{~m}$. This offers a perfect combination of soil, rain, humidity, and temperature' (Packages 15). In visual terms, these brands use pictures of exotic landscapes (Fig. 3B) and ethnic prints (Fig. 3 A, C) on their packages, consistent with the notions of Edenic Myth-making and the commodification of culture, as discussed before.

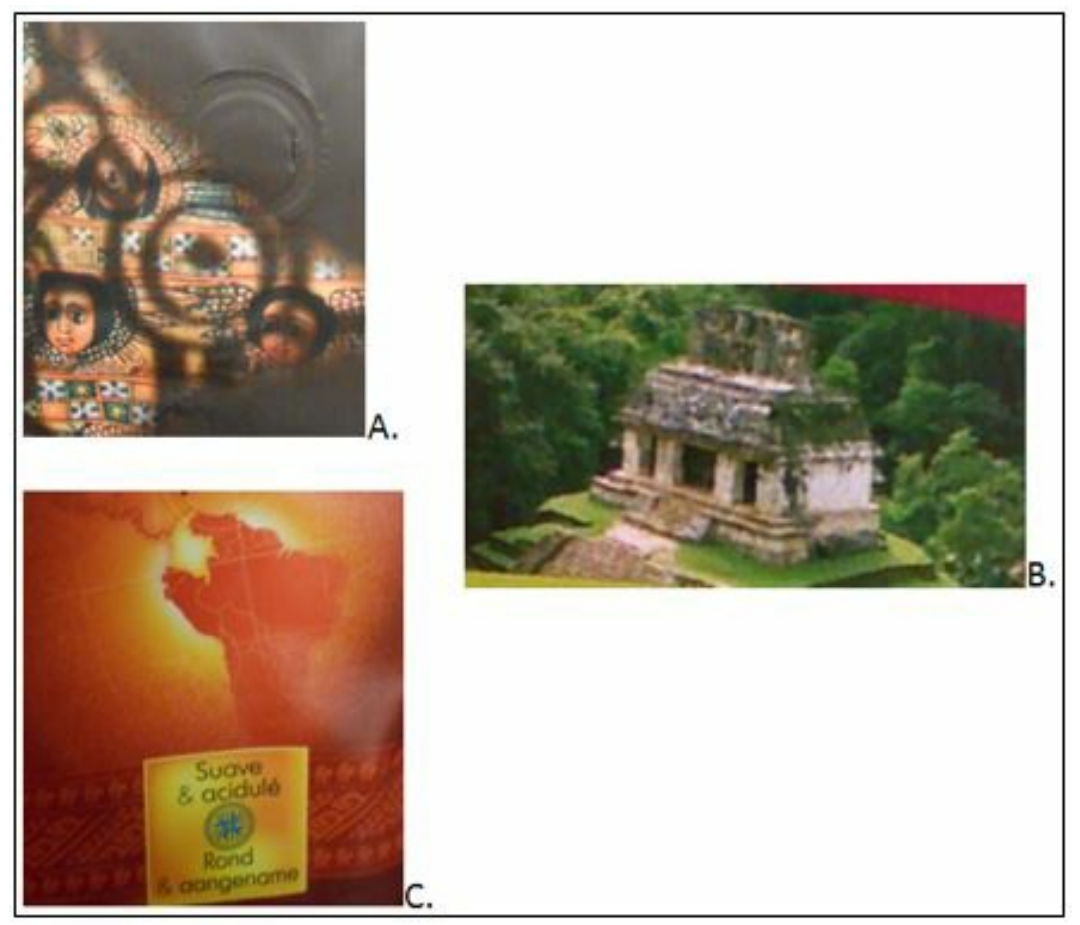

Figure 3. Origin pictures

6.21 The references to the origins of the coffee seem intended to transport consumers to faraway countries, thus fitting the concept of 'imaginative travel' (Urry 2000; 2007). The kind of imaginative travel evoked on these packages, however, does not raise awareness concerning the global interdependence between consumers in the North and producers in the South. By emphasizing the natural and untouched locations in which the coffees are grown and associating them with high quality, these brands actually transform the distance into an exclusive asset. In this regard therefore, the packages seem to magnify the physical distance between producer and consumer. By looking at the coffee packages, consumers can be transported to the other side of the world, only to be bewildered by the amazing differences between their own living environment and the ravishing mythical landscapes that produced the excellent coffee they are holding in their hands. The challenge for fair trade products thus entails avoiding the trap of Edenic Myth-making, as it might add to the fetish (cf. Cook \& Crang with regard to the double commodity fetish) instead of making people aware of the living conditions of the producers.

\section{Discussion}

7.1 This study is based on the analysis of the packaging materials of ground coffees offered within the Flemish market. We focus on how these packages attempt to address customers within the competitive environment of the supermarket and, more specifically, how the issue of defetishization operates in this context. The analysis does not reveal a consistent distinction between the packaging materials used by the different brand categories in our database.

7.2 One important distinction could be made with regard to the ways in which the brands of fair trade advocates and the regular and house brands referred to producers. The two fair trade advocates adopted a more personal approach, allowing the consumer to 'meet' the producer. Other labeled coffees adopted a more standardized approach, in which the producer remained an anonymous entity.

7.3 No clear distinctions could be drawn on other aspects. All of the selected packages placed heavy emphasis on the quality of the coffee. Moreover, references to the process of production were advanced within this context, emphasizing characteristics of the production process as the foundation for the excellent quality of the coffee. Nevertheless, most of the references presented a relatively uninformative/romanticized image of coffee production. Finally, we observed at least partial similarities between the packages of the two fair trade advocates and those of the unlabeled 'origin' coffees, in that they all contained references to the geographic origins of the coffee, often linked to the quality of the coffee. 
more 'personal' portrait of the producer. This strategy could re-work the fetish, however, through the use of romanticized images. The other packages remained much more abstract, with some providing no information on the producer at all. With regard to other aspects that could be perceived as contributing to defetishization, we observed that all product packages placed heavy emphasis on the quality of the product, which provided an important frame for information on place and process of production. Instead of 'lifting' the veil of commodity fetishism, these practices 'embellished' it.

In our introduction, we emphasized the challenges posed by the supermarket setting for the notion of a homogeneous fair trade message, due to internal and external competition. In this discussion, we relate the role of the consumer in this setting to our findings concerning the information that the packages provided on producer, process, and place of production. First, we believe that the use of romanticized images and descriptions in fair trade campaigns could be better understood by considering the consumer. The use of such images and descriptions could be seen as the consequence of efforts to resonate with the consumer public. Certain images might be more easily recognizable or more readily associated with fair trade. In this study, we had no data on consumer reactions to or interpretations of the packaging materials. In the literature, however, various scholars have argued that the public expects certain images when confronted with specific societal issues (e.g., Dean 2015 on homelessness; Campbell 2011 on famine). For this reason, although specific images could be characterized as romanticized or stereotypical, they could also be perceived as necessary in order to achieve recognition with the public the brands are trying to address (Dean 2015). A similar line of thought could be applied to explain the prevalence of quality information in the framing of both the process and the place of production. The central point in this regard is that the supermarket public extends 'beyond the 5 per cent of the population that are its [fair trade's] natural consumers' (Alexander \& Nicholls 2006: 1243). The introduction of fair trade products into the supermarket was thus expected to broaden the consumer base of fair trade products. However, as demonstrated in various studies, in order to appeal to a broader range of consumers, fair trade marketing shifted towards a focus upon product quality. It is thus the consumer (or, more precisely, perceptions about consumer preferences) that seems to stand in the way of profound defetishization on product packages.

Subsequent research could focus on the reception of fair trade packages by the consumer public. The production of such marketing materials should also be explored further. As argued by O'Boyle (2009: 8), 'constructions of identity in advertising are contingent and context bound and are as much about alleviating producer uncertainty as they are about the prevailing cultural climate or the putative preferences of consumers.'

\section{Conclusion}

8.1 Returning to our point about the complexity associated with fair trade (marketing) messages within the competitive supermarket setting, our results indeed do not provide any straightforward 'message' provided on all analyzed packages. The desire to broaden the fair trade market has produced a situation in which many different actors are present in this market. For this reason, and based on our findings, we argue that it is no longer accurate to speak of a fair trade network that offers a single, clear message to consumers. Instead, specifically within the supermarket setting, multiple actors (in this case, packages) appear with messages that resemble each other to some extent, while also exhibiting clear differences (e.g., abstract farmers/producers 'with faces;' mentioning/not mentioning the place of production; degree of focus on quality). These similarities and differences do not follow sharp dividing lines between categories that might be validated by some experts (e.g., who know the meaning of various labels and claims; who can distinguish between 'true' fair trade products and weaker imitations; or who are interested in the companies behind products). Average consumers are unlikely to make such distinctions consistently, due to the similarity of messages across the boundaries of the various categories. The packages could thus be seen as actors attempting to translate the message of the fair trade network to suit their interests (e.g., supporting farmers; building an image; maximizing sales), linked through a general desire to appeal to customers within a competitive market setting. This obviously imposes serious limitations on the potential of fair trade to develop into a genuine alternative to conventional trade.

\section{Acknowledgements}

This research was supported by research grant G096712N of the Research Foundation - Flanders to Lesley Hustinx. The authors wish to thank the two anonymous reviewers for their constructive and helpful comments.

\section{Notes}

In its most widely used definition, fair trade is described as 'A trading partnership, based on dialogue, transparency and respect, that seeks greater equity in international trade. It contributes to sustainable development by offering better trading conditions to, and securing the rights of marginalized producers and 


\section{Appendix 1}

Table 2. Overview of the selected packages and their characteristics.

\begin{tabular}{|c|c|c|c|c|c|c|c|c|c|c|}
\hline \multirow{3}{*}{$\begin{array}{l}\text { Packages } \\
\text { * }\end{array}$} & \multicolumn{3}{|c|}{ BRAND } & \multicolumn{6}{|c|}{ LABEL } & \multirow{3}{*}{$\begin{array}{l}\text { ORIGIN } \\
\begin{array}{l}\text { Origins in } \\
\text { name }\end{array}\end{array}$} \\
\hline & \multirow{2}{*}{$\begin{array}{l}\text { House } \\
\text { Brand }\end{array}$} & \multirow{2}{*}{$\begin{array}{l}\text { Regular } \\
\text { Brand }\end{array}$} & \multirow{2}{*}{$\begin{array}{l}\text { Fair } \\
\text { Trade } \\
\text { Advocate }\end{array}$} & \multicolumn{3}{|c|}{ 3rd Party } & \multirow{2}{*}{$\begin{array}{l}\text { Industry } \\
\text { Level }\end{array}$} & \multirow{2}{*}{$\begin{array}{l}\text { Company } \\
\text { Specific }\end{array}$} & \multirow{2}{*}{$\begin{array}{l}\text { No } \\
\text { Label }\end{array}$} & \\
\hline & & & & $\begin{array}{l}\text { Foir } \\
\text { Trade }\end{array}$ & $\begin{array}{c}\text { UTZ } \\
\text { Certified } \\
\end{array}$ & $\begin{array}{c}\text { Rainforest } \\
\text { Alliance }\end{array}$ & & & & \\
\hline Packages 1 & $x$ & & & & & & $x$ & & & \\
\hline Packages 2 & $x$ & & & $x$ & & & & & & \\
\hline Packages 3 & $x$ & & & $x$ & & & & & & \\
\hline Packages 4 & $x$ & & & & & & & & $x$ & $x$ \\
\hline Packages 5 & & & $\mathrm{x}$ & $x$ & & & & & & $x$ \\
\hline Packages 6 & & $x$ & & $x$ & & & & & & \\
\hline Packages 7 & & & $x$ & $x$ & & & & & & \\
\hline Packages 8 & $x$ & & & & & $x$ & & $\mathrm{x}$ & & $x$ \\
\hline Packages 9 & $x$ & & & & & & & & $x$ & $x$ \\
\hline $\begin{array}{l}\text { Packages } \\
10\end{array}$ & $x$ & & & & & & & & $x$ & $x$ \\
\hline $\begin{array}{l}\text { Packages } \\
11\end{array}$ & & $x$ & & & $x$ & & & & & \\
\hline $\begin{array}{l}\text { Packages } \\
12\end{array}$ & $x$ & & & & & & & $\mathrm{x}$ & & \\
\hline $\begin{array}{l}\text { Packages } \\
13\end{array}$ & $x$ & & & $x$ & & & & & & \\
\hline $\begin{array}{l}\text { Packages } \\
14 \\
\end{array}$ & $x$ & & & $x$ & & & & & & $x$ \\
\hline $\begin{array}{l}\text { Packages } \\
15\end{array}$ & $x$ & & & & & & & & $x$ & $x$ \\
\hline $\begin{array}{l}\text { Packages } \\
16\end{array}$ & & $x$ & & & & $x$ & & & & \\
\hline $\begin{array}{l}\text { Packages } \\
17\end{array}$ & $x$ & & & $x$ & & & & & & \\
\hline $\begin{array}{l}\text { Packages } \\
18\end{array}$ & $\mathrm{x}$ & & & & & & & & $\mathrm{x}$ & $x$ \\
\hline
\end{tabular}


*Packages are grouped according to brand. Different colors indicate different brands: one brand can encompass several packages, as different labels and/or names can be attributed to different packages of the same brand.

\section{References}

ALEXANDER, A. and Nicholls, A. (2006) 'Rediscovering consumer-producer involvement: A network perspective on fair trade marketing', European Journal of Marketing, Vol. 40, No. 11-12, p. 1236-1253.

[doi:10.1108/03090560610702795]

ALLEN, P. and Kovach, M. (2000) 'The capitalist composition of organic: The potential of markets in fulfilling the promise of organic agriculture', Agriculture and Human Values, Vol. 17, No. 3, p. 221-232. [doi:10.1023/A:1007640506965]

ARNOLD, N. and Hasse, R. (2015) 'Escalation of Governance: Effects of Voluntary Standardization on Organizations, Markets and Standards in Swiss Fair Trade', Sociological Research Online, Vol. 20, No.3: http://www.socresonline.org.uk/20/3/10/10.pdts. [doi:10.5153/sro.3734]

BARREY, S., Cochoy, F., and Dubuisson-Quellier, S. (2000) 'Designer, packager et merchandiser?: trois professionnels pour une même scène marchande', Sociologie du Travail, Vol. 42, No.3, p. 457-482. [doi:10.1016/S0038-0296(00)01089-X]

BELL, D. and Valentine, G. (1997) Consuming Geographies: We are where we eat New York: Routledge.

BRYANT, R. L., and Goodman, M. K. (2004) 'Consuming narratives: the political ecology of 'alternative' consumption', Transactions of the Institute of British Geographers, Vol. 29, No.3, p. 344-366. [doi:10.1111/j.0020-2754.2004.00333.x]

CAMPBELL, D. (2011) The Iconography of Famine. In G. Batchen, M. Gidley, N. Miller \& J. Prosser (Eds.), Picturing Atrocity: Reading photographs in crisis. London: Reaktion Books.

CARRIER, J. G. (2010) 'Protecting the environment the natural way: Ethical consumption and commodity fetishism', Antipode, Vol. 42, No.3, p. 672-689. [doi:10.1111/j.1467-8330.2010.00768.x]

COCHOY, F. (2007) A sociology of market-things: on tending the garden of choices in mass retailing. In M. Callon, Y. Millo \& F. Muniesa (Eds.), Market Devices, Malden: Blackwell Publishing. [doi:10.1111/j.1467954x.2007.00732.x]

COOK, I.and Crang, P. (1996) 'The World On a Plate: Culinary Culture, Displacement and Geographical Knowledges', Journal of Material Culture Vol.1, No.2, p.131-153. [doi:10.1177/135918359600100201]

CRANG, M. (1998) Cultural Geography. New York: Taylor \& Francis Group.

DE FERRAN, F. and Grunert, K. G. (2007) 'French fair trade coffee buyers purchasing motives: An exploratory study using means-end chains analysis', Food Quality and Preference, vol. 18, No.2, p. 218-229. [doi:10.1016/j.foodqual.2005.11.001]

DE PELSMACKER, P., Driesen, L. and Rayp, G. (2005) 'Do Consumers Care about Ethics? Willingness to Pay for Fair-Trade Coffee', Journal of Consumer Affairs, Vol. 39, No.2, p. 363-385. [doi:10.1111/j.17456606.2005.00019.x]

DEAN, J. (2015) 'Drawing What Homelessness Looks Like: Using Creative Visual Methods as a Tool of Critical Pedagogy', Sociological Research Online, Vol.20, No.1, http://www.socresonline.org.uk/20/1/2.html. [doi:10.5153/sro.3540] 


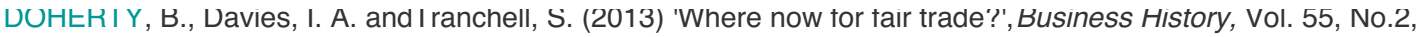
p. 161-189. [doi:10.1080/00076791.2012.692083]

FAIRTRADE INTERNATIONAL (2014). Strong Producers, Strong Future: Annual Report 2013-14. Bonn: Fairtrade International.

FRIDELL, G. (2007). 'Fair-Trade Coffee and Commodity Fetishism: The Limits of Market-Driven Social Justice', Historical Materialism, Vol.15, No.4, p. 79-104. [doi:10.1163/156920607X245841]

GEYSMANS, R. (forthcoming). 'The Evolution of the Discourse of a Belgian Fair Trade Organization: A TwoDimensional History', Social Enterprise Journal.

GOFFMAN, E. (1974). Frame Analysis: An Essay on the Organization of Experience. Harmondsworth: Penguin Books.

GOODMAN, M. K. (2004) 'Reading fair trade: political ecological imaginary and the moral economy of fair trade foods', Political Geography, Vol. 23, No.7, p. 891-915. [doi:10.1016/j.polgeo.2004.05.013]

GOODMAN, M. K. (2010) 'The mirror of consumption: Celebritization, developmental consumption and the shifting cultural politics of fair trade', Geoforum, Vol.41, No.1, p. 104-116. [doi:10.1016/j.geoforum.2009.08.003]

HARVEY, D. (1990) 'Between Space and Time: Reflections on the Geographical Imagination',Annals of the Association of American Geographers, Vol.80, No.3, p. 418-434. [doi:10.1111/j.14678306.1990.tb00305.x]

HUDSON, I. and Hudson, M. (2003) 'Removing the Veil?: Commodity Fetishism, Fair Trade, and the Environment', Organization \& Environment, Vol.16, No.4, p. 413-430. [doi:10.1177/1086026603258926]

HUDSON, I., Hudson, M. and Fridell, M. (2013). Fair Trade, Sustainability and Social Change. New York: Palgrave Macmillan. [doi:10.1057/9781137269850]

JACKSON, P. (1999) 'Commodity Cultures: The Traffic in Things', Transactions of the Institute of British Geographers, Vol. 24, No.1, p. 95-108. [doi:10.1111/j.0020-2754.1999.00095.x]

JOHNSTON, J., Biro, A. and MacKendrick, N. (2009) 'Lost in the Supermarket: The Corporate-Organic Foodscape and the Struggle for Food Democracy', Antipode, Vol.41, p. 509-532. [doi:10.1111/j.14678330.2009.00685.x]

LOW, W. and Davenport, E. (2005a) 'Has the Medium (Roast) Become the Message? The Ethics of Marketing Fair Trade in the Mainstream', International marketing review, Vol.22, No.5, p. 494-511. [doi:10.1108/02651330510624354]

LOW, W. and Davenport, E. (2005b) 'Postcards from the edge: maintaining the 'alternative' character of fair trade', Sustainable Development, Vol.13, No.3, p. 143-153. [doi:10.1002/sd.275]

LYON, S. (2006) 'Evaluating fair trade consumption: politics, defetishization and producer participation', International Journal of Consumer Studies, Vol. 30, No.5, p. 452-464. [doi:10.1111/j.14706431.2006.00530.x]

MARX, K. (1976) [1867]. Capital: A Critique of Political Economy Part 1. London: Penguin Books.

MOORE, G. (2004) 'The Fair Trade Movement: Parameters, Issues and Future Research',Journal of Business Ethics, Vol. 53, No.1, p.73-86. [doi:10.1023/B:BUSI.0000039400.57827.c3]

O'BOYLE, N. (2009) 'Analysing an Advertising Campaign: Towards an Integrated Cultural-Industrial Analysis', Sociological Research Online, Vol.14, No.4, http://www.socresonline.org.uk/14/4/12.html. [doi:10.5153/sro.1960]

RAYNOLDS, L. T., Murray, D. and Taylor, P. L. (2004) 'Fair trade coffee: building producer capacity via global networks', Journal of International Development, Vol.16, No.8, p. 1109-1121. [doi:10.1002/jid.1136]

RAYNOLDS, L., Murray, D. and Heller, A. (2007) 'Regulating sustainability in the coffee sector: A comparative analysis of third-party environmental and social certification initiatives', Agriculture and Human Values, Vol.24, No.2, p.147-163. [doi:10.1007/s10460-006-9047-8]

RAYNOLDS, L. T. (2009) 'Mainstreaming Fair Trade Coffee: From Partnership to Traceability', World Development, Vol.37, p. 1083-1093. [doi:10.1016/j.worlddev.2008.10.001]

REED, D. (2009) 'What do Corporations have to do with Fair Trade? Positive and Normative Analysis from a Value Chain Perspective', Journal of Business Ethics, Vol. 86, No.0, p.3-26. [doi:10.1007/s10551-008- 
REIN, M. and Schön, D. (1993) Reframing Policy Discourse. In F. Fischer \& J. Forester (Eds.),The Argumentative Turn in Policy Analysis and Planning Durham: Duke University Press, p. 145-166. [doi:10.1215/9780822381815-007]

REINECKE, J., Manning, S. and von Hagen, O. (2012) 'The Emergence of a Standards Market: Multiplicity of Sustainability Standards in the Global Coffee Industry', Organization Studies, Vol.33, No.5-6, p. 791814. [doi:10.1177/0170840612443629]

RENARD, M. C. (2003) 'Fair trade: quality, market and conventions', Journal of Rural Studies: International Perspectives on Alternative Agro-Food Networks: Quality, Embeddedness, Bio-Politics, 19, p. 87-96.

RENARD, M. C. (2005) 'Quality certification, regulation and power in fair trade', Journal of Rural Studies, Vol.21, No.4, p.419-431. [doi:10.1016/j.jurstud.2005.09.002]

URRY, J. (2000) Sociology Beyond Societies: Mobilities for the Twenty-First Century. New York: Taylor \& Francis.

URRY, J. (2007) Mobilities. Cambridge: Polity Press.

VARUL, M. (2008) 'Consuming the campesino: fair trade marketing between recognition and romantic commodification', Cultural Studies,Vol. 22, No.5, p. 654-679. [doi:10.1080/09502380802245910]

WATSON, M. (2006) 'Towards a Polanyian perspective on fair trade:market-based relationships and the act of ethical consumption', Global Society, Vol.20, No.4, p. 435-451. [doi:10.1080/13600820600929788]

WEBB, J. (2007) 'Seduced or Sceptical Consumers? Organised Action and the Case of Fair Trade Coffee', Sociological Research Online,Vol.12, No.3, http://www.socresonline.org.uk/12/3/5.html. [doi:10.5153/sro.1536]

WHATMORE, S. and Thorne, L. (1997) Nourishing networks: Alternative geographies of food. In D. Goodman \& M. Watts (Eds.), Globalising Food: Agrarian Questions and Global Restructuring. D. Goodman and MJ Watts. London, Routledge, p. 287-303. London: Routledge.

WRIGHT, C. (2004) 'Consuming lives, consuming landscapes: interpreting advertisements for cafédirect coffees', Journal of International Development, Vol. 16, No.5, p. 665-680. [doi:10.1002/jid.1119]

WRIGHT, C. (2009) 'Fairtrade Food: Connecting producers and consumers', In D. Inglis \& D. Gimlin (Eds.),The globalization of food. Oxford: Berg. 